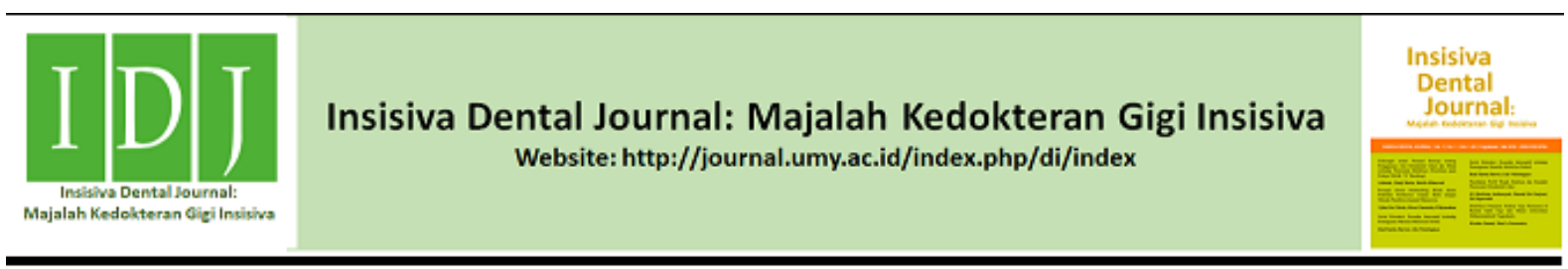

Literature Review

\title{
Premature Loss dan Perkembangan Rahang
}

Premature Loss and Jaw Development

\section{Laelia Dwi Anggraini ${ }^{1, *}$, Rinaldi Budi Utomo², Sunarno ${ }^{3}$, dan Dibyo Pramono²}

${ }^{1}$ Program Studi Kedokteran Gigi, Fakultas Kedokteran dan Ilmu Kesehatan, Universitas Muhammadiyah Yogyakarta, Jalan Brawijaya, Kasihan, Bantul, Indonesia.

${ }^{2}$ Fakultas Kedokteran Gigi, Universitas Gadjah Mada, Jalan Denta, Sinduadi, Mlati, Sleman, Yogyakarta, Indonesia.

${ }^{3}$ Fakultas Teknik, Universitas Gadjah Mada, Jalan Grafika, Sinduadi, Mlati, Sleman, Yogyakarta, Indonesia.

Received date: Mei 21 $1^{\text {st }}, 2018$; reviewed date: June $10^{\text {th }}, 2018$; revised date: August $26^{\text {th }}, 2018$; accepted date: October $31^{\text {st }}, 2018$ DOI : $10.18196 /$ di. 7297

\begin{abstract}
Abstrak
Premature loss adalah kondisi dimana gigi desidui yang sudah tanggal sebelum waktunya sementara gigi permanen pengganti belum tumbuh. Kehilangan gigi desidui yang terlalu dini akan berpengaruh pada keberhasilan erupsi gigi apabila ada pengurangan ruang pada lengkung gigi. Kondisi premature loss terkait pula dengan perkembangan rahang. Rahang adalah bagian dari struktur total kepala dan setiap rahang bisa mempunyai hubungan posisional yang bervariasi terhadap struktur lain dari kepala, variasi semacam itu bisa terjadi pada ketiga bidang yaitu sagital, vertikal, dan lateral. Setiap kondisi patologis yang mempengaruhi pertumbuhan rahang bisa menimbulkan efek besar terhadap oklusi gigi. Pertumbuhan maksila dipengaruhi oleh pertumbuhan otak, pertumbuhan tulang cranial dan nasal septal memberikan pengaruh signifikan terhadap pergerakan maju mundur maksila. Mandibula merupakan tulang kraniofasial yang sangat mobile dan merupakan tulang yang sangat penting karena terlibat dalam fungsi-fungsi vital antara lain pengunyahan, pemeliharaan jalan udara, berbicara, dan ekspresi wajah. Gerakan pertumbuhan mandibula pada umumnya dipengaruhi oleh perubahan yang terjadi di maksila. Pertumbuhan prosesus alveolaris sangat aktif selama erupsi dan berperan penting selama erupsi serta terus memelihara hubungan oklusal selama pertumbuhan vertikal maksila dan mandibula. Kesimpulan dari telaah literatur ini yaitu kondisi rongga mulut karena premature loss secara langsung atau tidak langsung berpengaruh pada tumbuh kembang rahang.
\end{abstract}

Kata Kunci: Perkembangan rahang; Premature loss

\begin{abstract}
Premature loss is a condition where deciduous teeth are prematurely lost while permanent replacement teeth have not yet erupted. Losing a deciduous tooth too early will affect the teeth eruption if a diminishment of space were to happen on the dental arch. The condition of premature loss also affects jaw development. The jaw is a part of the whole structure of the head, with each jaw capable of having a positional relationship that varies towards the other structures of the head. Those variations can occur on three planes, which are the sagittal, vertical, and lateral planes. Every pathological condition that affects the development of the jaw can also have a significant impact on dental occlusion. Maxillary growth correlates with brain growth. The growth of the cranial and nasal septal bone has significant effects on the maxilla's forward and backward movements. The mandible is a craniofacial bone that is very mobile and very important because it is involved in several vital functions such as chewing, maintaining the airway, talking, and facial expression. The process of mandibular growth, in most cases, is affected by changes that occur in the maxilla. The development of the alveolar process is very active during eruptions and plays a vital role throughout the eruptions. It also maintains the occlusal relationship throughout the vertical growth of the maxilla and the mandible. It can be concluded that the condition of the oral cavity caused by premature loss will directly or indirectly affect the development of the jaw.
\end{abstract}

Keywords: Jaw development; Premature loss

\footnotetext{
* Corresponding author, e-mail: laelia.dwi@umy.ac.id
} 


\section{PENDAHULUAN}

Premature loss adalah kondisi dimana gigi desidui yang sudah tanggal sebelum waktunya sementara gigi permanen pengganti belum tumbuh. Penyebabnya selain karena trauma yang mengakibatkan gigi tanggal awal, juga karies yang parah sehingga menyebabkan gigi harus dicabut. Selain itu, adanya kelainan kongenital menyebabkan gigi tidak tumbuh (anodonsia), di samping juga karena penyakit periodontal yang parah menyebabkan gigi goyah (luksasi) dan harus dicabut sebelum waktunya. Terdapatnya keganasan neoplasma juga menyebabkan gigi harus dicabut sebelum waktunya. Selain itu, adanya penyakit sistemik yang mengganggu pola tumbuh kembang rahang juga menyebabkan gigi tanggal sebelum waktunya. ${ }^{1} \mathrm{Hal}$ ini terjadi karena terdapat perbedaan waktu tanggal gigi desidui dan waktu tumbuh gigi permanen.

\section{PEMBAHASAN}

Pola pertumbuhan gigi desidui dan gigi permanen dapat dicermati pada gambar 1 yang menjelaskan tentang pola pertumbuhan gigi permanen, dimana gigi desidui cmım2 akan digantikan gigi permanen CM1M2. Adanya perbedaan lebar ini disebut dengan lee way space yang besarnya untuk rahang atas 1,7 $\mathrm{mm}$ dan rahang bawah $0,9 \mathrm{~mm}$.

Gambar 2 menunjukkan periodisasi pertumbuhan gigi desidui. Periode ini ditandai dengan pertumbuhan gigi incisivus sentral rahang bawah pada usia 6 bulan, diikuti gigi incisivus sentral rahang atas pada usia 8 bulan, dan seterusnya sampai semua gigi diharapkan tumbuh sebelum usia 33 bulan.

Gambar 3 menunjukkan periodisasi pertumbuhan gigi permanen. Periode ini ditandai dengan pertumbuhan gigi permanen, ialah incisivus sentral rahang bawah pada usia 6 tahun, diikuti gigi incisivus sentral rahang atas pada usia 7 tahun, dan seterusnya sampai semua gigi diharapkan tumbuh sebelum usia 21 tahun.

Penatalaksanaan dari premature loss pada gigi anak membutuhkan pertimbangan yang sangat cermat dari dokter gigi karena konsekuensi dari pengaturan ruang pada lengkung gigi akan mempengaruhi perkembangan gigi hingga dewasa. Kehilangan gigi desidui yang terlalu dini akan berpengaruh pada keberhasilan erupsi gigi apabila ada pengurangan ruang pada lengkung gigi.

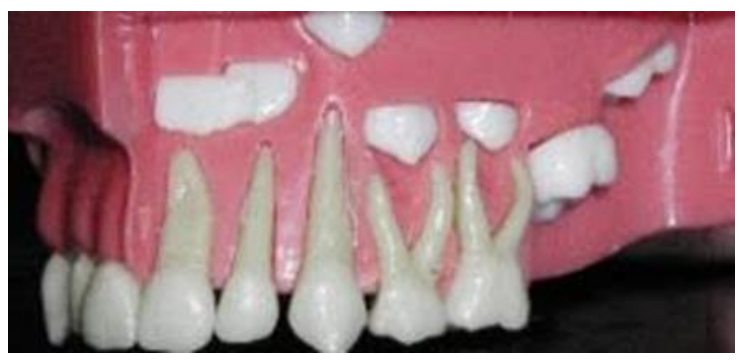

Gambar 1. Pola pertumbuhan gigi desidui dan gigi permanen

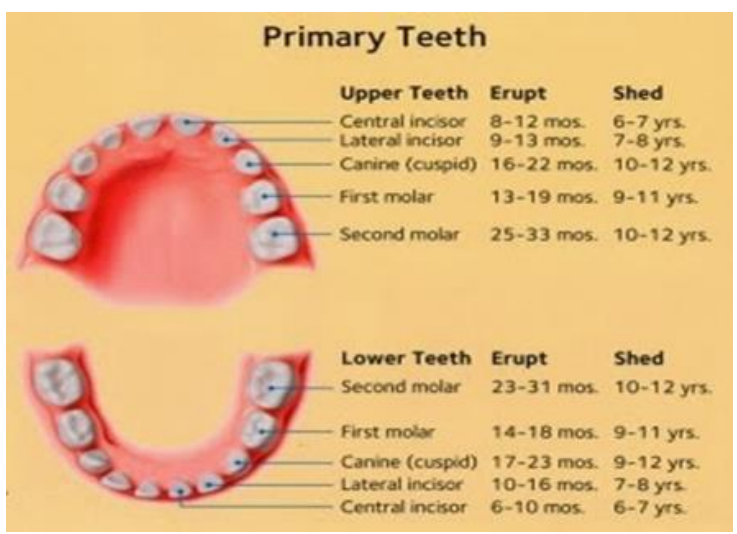

Gambar 2. Periodisasi pertumbuhan gigi desidui

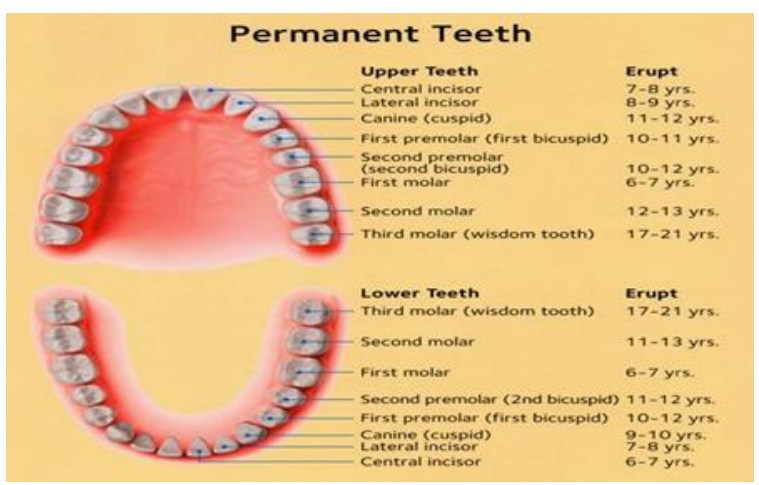

Gambar 3. Periodisasi pertumbuhan gigi permanen 
Adapun pada sisi yang lain, intervensi yang tepat pada waktunya terhadap ruang pada lengkung rahang dapat mempertahankan ruang untuk erupsi gigi permanen. Kunci dari manajemen pertahanan ruang pada desidui adalah mengetahui masalah yang mana yang harus dirawat. $^{2}$ Kehilangan caninus atau molar pertama desidui menyebabkan pergeseran mesial/distalgigi sebelahnya. Kehilangan gigi incisivus jarang berpengaruh terhadap tumbuh kembang rahang. ${ }^{3}$

Premature loss menyebabkan terjadinya perubahan pada panjang lengkung gigi. ${ }^{2}$ Lengkung gigi yang tadinya cukup untuk menampung gigi yang akan tumbuh, menjadi berkurang karena pergeseran gigi di sampingnya sehingga memperkecil area kosong yang ada. Kehilangan gigi juga mengakibatkan terjadinya gangguan fungsi pengunyahan, anak menjadi tidak dapat makan dengan baik karena beberapa gigi tidak dapat berfungsi maksimal. Beberapa pasien anak yang ditemui mempunyai gangguan estetis, anak menjadi tidak percaya diri, sehingga mengganggu penampilan. Terdapatnya gangguan bicara sehingga anak tidak dapat mengucapkan kata dengan jelas, kadang mendesis karena gigi anteriornya tidak ada. Ketidakberadaan gigi juga menyebabkan perkembangan kebiasaan buruk pasien, misal pasien menjadi mengunyah satu sisi sehingga sisi lainnya penuh karang gigi. Munculnya masalah psikologis lainnya, ialah anak menjadi rendah diri serta tidak percaya diri. Adapun secara klinis, tampak pergeseran gigi menempati ruang yang ada. $^{3}$

Rahang adalah bagian dari struktur total kepala dan setiap rahang bisa mempunyai hubungan posisional yang bervariasi terhadap struktur lain dari kepala, variasi semacam itu bisa terjadi pada ketiga bidang yaitu sagital, vertikal, dan lateral. Posisi rahang juga dihubungkan dengan basis anterior kranium dan masingmasing rahang dapat bervariasi dalam hubungannya terhadap kranium. ${ }^{2}$
Rahang memiliki dua komponen yaitu tulang alveolar yang merupakan tempat gigi-geligi dan tulang basal yang membentuk struktur utama rahang. Pembagian tulang- tulang rahang menjadi komponen basal dan alveolar bersifat artifisial karena keduanya berasal dari tulang yang sama, tetapi pembagian tersebut dapat diterima karena mengalami perkembangan dan memiliki fungsi yang berbeda. Setiap kondisi patologis yang mempengaruhi pertumbuhan rahang bisa menimbulkan efek besar terhadap oklusi gigi. ${ }^{4}$ Malformasi kongenital baik bawaan maupun dapatan, trauma, serta infeksi selama tahun- tahun pertumbuhan dapat mempengaruhi pertumbuhan dan perkembangan rahang. ${ }^{5}$

Pertumbuhan maksila dipengaruhi oleh pertumbuhan otak, pertumbuhan tulang cranial dan nasalseptal memberikan pengaruh signifikan terhadap pergerakan maju mundur maksila dari lahir hingga umur 7 tahun. Setelah umur tujuh tahun hingga dewasa, pengaruh-pengaruh tersebut berkurang secara drastis seiring pertumbuhan sutural dan pertumbuhan permukaan intramembranosa. Pertumbuhan postnatal maksila seluruhnya terjadi dengan osifikasi intramembran karena tidak terdapat kartilago. ${ }^{6}$ Pertumbuhan maksila terjadi melalui dua cara yaitu aposisi sutura yang menghubungkan maksila dengan kranium dan basis kranial serta remodeling tulang. Sementara maksila tumbuh ke bawah dan depan, permukaan anteriornya mengalami remodeling. Hampir seluruh permukaan anterior maksila mengalami resorpsi kecuali daerah disekitar spina nasalis anterior. Saat terjadi pertumbuhan maksila ke arah bawah dan depan, ruang antara sutura yang terbuka diisi oleh proliferasi tulang. Aposisi terjadi pada kedua sisi sutura sehingga tulang tempat perlekatan maksila bertambah besar, tepi posterior maksila yang merupakan daerah tuberositas mengalami aposisi sehingga menambah ruang untuk tempat erupsi gigi molar permanen. Aposisi permukaan terjadi di 
sebelah anterior lengkung tulang maksila, dimana panjang maksila akan bertambah setelah umur dua tahun yang terjadi akibat dari tuberositas maksila dan dengan pertumbuhan sutura sepanjang tulang palatal. $^{7}$

Mandibula merupakan tulang kraniofasial yang sangat mobile dan merupakan tulang yang sangat penting karena terlibat dalam fungsi-fungsi vital antara lain pengunyahan, pemeliharaan jalan udara, berbicara, dan ekpresi wajah. Mandibula adalah tulang pipih berbentuk $U$ dengan mekanisme pertumbuhan melalui proses osifikasi endokondral maupun aposisi periosteal (osifikasi intramembranosa) dan di mandibula merupakan tempat melekatnya otot-otot serta gigi. Pertumbuhan mandibula ada dua macam yaitu: a). Pola pertama, bagian posterior mandibula dan basis kranium tetap, sementara dagu bergerak ke bawah dan ke depan; b). Pola kedua, dagu dan korpus mandibula hanya berubah sedikit sementara pertumbuhan sebagian besar terjadi pada tepi posterior ramus, koronoid dan kondilus mandibula. Gerakan pertumbuhan mandibula pada umumnya dipengaruhi oleh perubahan yang terjadi di maksila.

Dagu bergerak ke bawah dan depan hanya sebagai akibat pertumbuhan kondilus dan tepi posterior ramus mandibula. Korpus mandibula bertambah panjang melalui aposisi tepi posteriornya, sementara ramus bertambah tinggi melalui osifikasi endokondral pada kondilus dan remodeling tulang. Selain tumbuh ke bawah dan ke depan, mandibula juga tumbuh ke lateral melalui aposisi permukaan lateral korpus, ramus, dan alveolaris mandibula. Untuk mengimbangi aposisi lateral, terjadi resorpsi pada permukaan lingualnya. Pembentukan prosesus alveolaris dikontrol oleh erupsi gigi dan resorpsi bila gigi tanggal ataupun diekstraksi. Gigi pada kedua lengkung tidak menjadi protrusi ketika maksila dan mandibula tumbuh dan berpindah tempat karena adanya relasi interkuspal gigi. Pertumbuhan prosesus alveolaris sangat aktif selama erupsi dan berperan penting selama erupsi serta terus memelihara hubungan oklusal selama pertumbuhan vertikal maksila dan mandibula. ${ }^{4}$

Penyebab kehilangan atau penyempitan ruang adalah meliputi a. premature loss dari gigi desidui, dimana masing-masing dari gigi mempunyai pengaturan ruang tersendiri dari hubungan oklusal yang didapatkan dari aksi kekuatan individual. Jika relasi antar gigi terjadi altered, drifting atau tipping, maka akan terjadi kehilangan ruang atau penambahan ruang; b. Kekuatan ke arah mesial dari erupsi gigi posterior, dimana ada kecenderungan yang sangat kuat dari gigi untuk bergerak ke arah mesial bahkan saat pertama kali erupsi di dalam mulut. Fenomena ini disebut mesial drifting tendency. c. Distal adjustment dari gigi anterior mandibula, saat insisivus permanen rahang bawah erupsi, gigi kaninus susu berpindah ke arah distal dan bukal pada kasus premature loss, dimana ukuran sebuah gigi dalam lengkung rahang yang mengecil, gigi kaninus susu dapat tanggal lebih dini karena tekanan resorpsi dari gigi insisivus lateral yang ektopik. d. Ankylosis, ankylosis biasanya terjadi antara umur 6 dan 12 tahun yang itandai dengan membran periodontal yang hilang dan formasi tulang yang membentuk gabungan antara lamina dura dan sementum. ${ }^{8}$ Penggabungan tulang ini mencegah gigi erupsi, sedangkan gigi yang lain dalam lengkung gigi tetap erupsi. ${ }^{9}$ Gigi-gigi yang berdekatan bisa saling mendesak atau berpindah ke ruang oklusal dari gigi yang ankylosis dan mengurangi panjang lengkung rahang. ${ }^{10}$ e. Congenital missing teeth, kehilangan gigi secara kongenital lebih sering ditemukan pada gigi permanen daripada gigi desidui. ${ }^{11}$ Evaluasi ortodonti sangat dibutuhkan pada saat penentuan apakah ruang harus dipertahankan untuk pertimbangan ortodonti atau prostodonti atau ditutup. ${ }^{12}$ 


\section{KESIMPULAN}

Kesimpulan dari tulisan ini adalah kondisi rongga mulut karena premature loss secara langsung atau tidak langsung berpengaruh pada tumbuh kembang rahang.

\section{DAFTAR PUSTAKA}

1. Cameron. Caries in Children, Handbook of Pediatric Dentistry, CV Mosby, USA. Chapter 1. 2013.

2. Das, Beena, dan Azher. Oral health status of 6 and 12 year old school going children in Bangalore city: An epidemiological study, J. Indian Soc Pedod Prevent Dent, Kamataka, India. 2009; 27(1). 6-8.

3. Finn. Pediatric Dentistry, Mosby \& Co, USA, 2014;161-166.

4. Kidd, E. A.M. dan Bechal, S.J, Dental Caries Dasar-dasar Karies, Penyakit dan Penanggulangannya, EGC, Jakarta. 2009; 18-76.

5. Mc. Donald dan Avery. Dentistry for the Child and Adolescent, ed. 9, Mosby Co., St. Louis, Missouri. 2015; 221-223.

6. Nanda. Biomechanic in Clinical Orthodonsia, Saunders Co., St. Louis, Missouri. 2004; 21-23.

7. Snawder, K.D., Handbook of Clinical Pedodontics, St Louis, Missouri, USA. 2017; 242-275.

8. Pinkham. Pediatric Dentistry, edisi 4, WB Saunders and Co, Philadelphia. 2013; 242-256.

9. Koch, G., Kreiborg, S., \& Andreasen, J. O. Eruption and shedding of teeth. Pediatric Dentistry. A Clinical Approach. 3rd ed. Oxford: Wiley-Blackwell, 2017; 40-54.

10. Aludden, H. C., \& Jensen, T. Dentoalveolar Segmental Osteotomy Combined with Orthodontic Treatment for an Impacted and Ankylosed Upper Canine: A Case Report. Open Journal of Stomatology, 2016; 6(4): 97-102.
11. Rakhshan, V. Congenitally missing teeth (hypodontia): A review of the literature concerning the etiology, prevalence, risk factors, patterns and treatment. Dental research journal, 2015; 12(1): 1-13.

12. Widyastuti, Y., \& Kemal, Y. Perawatan ortodontik pada pasien periodontal kompromi. Makassar Dental Journal, 2015; 4(3): 98-102. 